\title{
Reindustrialización y recomposición del movimiento obrero norteamericano, 1960-1988
}

\author{
Pablo A. Pozzi
}

En una entrevista realizada en 1976, Enrico Porente, un pionero del sindicalismo norteamericano por rama de industria, veterano de la IWW (Industrial Workers of the World), del sindicato del vestido (ACWU) y de la CIO (Congress of the Industrial Organizations), refle$x$ ionaba sobre su pasado como activista sindical y concluía diciendo: "El movimiento obrero en este país no es el mismo de antes. Había lucha de clases; ahora todo es negociación. El movimiento obrero necesita un tercer renacimiento. El primero fue en 1905 con el nacimiento de la IWW; el segundo con la CIO en 1936. Ahora necesitamos un tercero. La mayoría de nuestra gente todavia no tiene poder." 1

Los dos periodos, 1905 y 1936, que menciona Porente marcan cambios en la organización y métodos de lucha de la clase obrera norteamericana, que a su vez se basan y son la síntesis de los cambios que ocurren en la economía norteamericana y en la composición de la misma clase obrera. Si tomamos esto en cuenta, entonces quizás podríamos pensar que el "tercer renacimiento", o momento de cambio y síntesis en la historia de la clase, no está tan lejos como se podría pensar. De hecho, durante los últimos veinte años han ocurrido profundos cambios en la estructura económica de los Estados Unidos. Esta reestructuración, llamada por algunos autores una "revolución científico-técnica" y por otros una "reindustrialización", "2 está cambiando la composición de la clase obrera norteamericana. El origen de esta situación ha sido la reducción del número de obreros industriales altamente especializados y bien pagados, y el aumento de trabajadores no calificados y con bajo nivel salarial en el sector servicios. Se desarrolla lo que un analista llamó la "MacDonaldización" de la economía norteamericana. ${ }^{3}$ Debido a esto, el peso social de los trabajadores no calificados, principalmente conformados por negros, hispano-norteamericanos y mujeres, se ha tornado preponderante como fuerza de trabajo.

Hay muchos datos que marcan esta reestructuración. Un estudio publicado el 6 de febrero de 1986 por la Oficina de Asesoramiento

1 Citado en James R. Green, The World of the Worker, New York, Hill and Wang, 1890, p. 247. La IWW y la CIO estaban organizadas por tendencias de izquierda y planteaban la organización por rama de industria y no por oficio, como hacía la American Federation of Labor (AFL), La CIO se fusiona con la AFL en 1955 para formar la AFL-CIO.

2 Véase Sam Marcy, High Tech, Low Pay, New York, World View Pub., 1986; Fred Block, "The Myth of Reindustrialization", Socialist Review, 73, Vol. 14, No. 1, Jan.-Feb. 1984; David Gordon, Richard Edwards y Michael Reich, Segmented Work, Divided Workers, New York, Cambridge University Press, 1983; y Barry Bluestone y Bennet Harrison, The Deindustrialization of America, New York, Basic Books, 1982. 1983.

"Bruce Steinberg, "The Mass Market is Splitting Apart", Fortune, November 28, 
Tecnológico del Congreso de los Estados Unidos planteaba que entre 1979 y 1984 casi once millones y medio de trabajadores perdieron sus empleos. "Casi la mitad de todos los trabajadores desplazados en este periodo trabajaban en industrias manufactureras tales como metalurgia, automotriz, maquinaria, textil y vestido. [De los que volvieron a encontrar trabajo, casi] $45 \%$ lo hizo por menor salario y dos tercios de ésos recibían un ingreso $80 \%$ menor que el anterior." El informe vaticinabä que "[d]ado el ritmo de cambio tecnológico y de estructura económica, [muchos más] trabajadores se verán rezagados".

Con respecto a la naturaleza del cambio, el informe planteaba que el $95 \%$ de las nuevas fuentes de trabajo creadas durante el periodo estudiado corresponde al sector servicios. El salario promedio de este sector era casi $20 \%$ menor que el salario industrial. ${ }^{4}$ De hecho, el desarrollo de la economía norteamericana durante las dos últimas décadas está afectando los sectores de trabajadores mejor pagados y reduciéndolos a niveles inferiores; esto tiene efectos en la relación entre los trabajadores negros, tradicionalmente más postergados, y los blancos, y también actúa como homogeneizador. Sin embargo, el impacto sc zioeconómico ha sido soslayado y también ocultado gracias a la expansión del sistema de crédito. En este sentido, si bien el nivel de vida de los trabajadores norteamericanos, en relación con otros países industrializados, se mantiene alto, lo hace a costa de aumentar el endeudamiento familiar. Hacia 1979 un obrero norteamericano debía $27 \%$ de su salario antes de percibirlo; entre 1968 y 1979 la deuda familiar nacional aumentó de $89 \mathrm{mil}$ millones a 307 mil millones de dólares. ${ }^{5}$ El significado de esto es que en un momento en que aumenta el desempleo y decae el ingreso familiar, la crisis social implícita es mucho más profunda que la crisis mundial de 1929. Esto último también produce un cambio en el balance de poder político a favor de aquellos sectores de trabajadores menos privilegiados, lo que a su vez hace impacto sobre el sistema político del país y el desarrollo de los conflictos sociales.

I. El sistema norteamericano que se construyó después de la segunda Guerra Mundial se basó, entre otras cosas, en un acuerdo entre el capital y el trabajo organizado en torno a la expansión económica. Como señala la revista Fortune sobre los primeros acuerdos de productividad entre General Motors Corp. y el sindicato automotriz (United Auto Workers: UAW) de 1948 a 1950: "GM puede haber pagado mil millones de dólares por la paz [pero] hizo negocio. General Motors recuperó el control sobre [. . .] las funciones gerenciales cruciales". 6 Aumentó el número de contratos que incorporaban cláusulas de "derechos de la gerencia". Se estableció que "el derecho a contratar, promover, despedir o disciplinar a causa de y para mantener el orden y la eficiencia de los trabajadores, es responsabilidad única de la Corporación [. . .] Además, los productos que deben ser manufacturados, la localización de las plantas,

1 El salario promedio en la manufactura era 9.18 dólares la hora, mientras que en la actividad terciaria era 7.52 dólares.

5 Green, op. cit., p. 215.

6 Citado en William Serrin, The Company and the Union, New York, Vintage, 1974 , p. 170. 
las fechas de producción, los métodos, procesos y medios de manufacturar, son sola y exclusivamente de la responsabilidad de la gerencia" " El economista Richard Lester resalta el logro cuando observa acerca de los mineros: "El sindicato ha estado presionando sobre las huelgas no autorizadas a través de multas y amenazas de expulsión de los afiliados individuales. En comparación, durante los trece años previos a 1950 se promediaban paros nacionales cada 18 meses."'8

Según este acuerdo, los sindicatos purgaban a los activistas más combativos y aceptaban que las corporaciones retuvieran un control absoluto sobre la producción, la tecnología, la ubicación de las plantas, la inversión y la comercialización del producto. A cambio, las uniones eran aceptadas como representantes legítimos de los intereses de los trabajadores. Se esperaba que negociaran a favor de los intereses económicos inmediatos de sus afiliados, pero no que desafiaran el control de los patrones sobre la empresa. Así, el sindicalismo ayudaba a mantener una fuerza de trabajo ordenada y disciplinada mientras que los patrones recompensaban a los trabajadores con una parte del ingreso debido al aumento en la productividad, con mayor estabilidad en el trabajo y mejores condiciones laborales. De hecho, durante el periodo 1950-1970, el salario disponible del trabajador organizado aumentó en términos reales, lo mismo que mejoró la estabilidad y las condiciones de trabajo. ${ }^{9}$ En 1979 una encuesta demostró que los trabajadores sindicalizados tenían un ingreso promedio de 262 dólares semanales, o sea 13886 al año, suponiendo un empleo anual de tiempo completo, mientras que los no organizados ganaban 221 dólares semanales, es decir 11713 anuales. ${ }^{10}$

Si bien el pacto entre capital y trabajo siempre fue relativamente tenue, fue más que suficiente para detener durante este periodo el desarrollo de los conflictos sociales tal como venian ocurriendo desde 1930. Queda claro que hubo momentos tormentosos, como por ejemplo entre 1957 y 1958 cuando un intento por parte de las corporaciones de avanzar en contra del sindicalismo desató una serie de medidas de fuerza que culminaron en una épica huelga metalúrgica de 116 días; y el conflicto con General Electric durante tres semanas de 1960, que se caracterizó por los altos niveles de violencia entre los patrones y los huelguistas. ${ }^{11}$

Un resultado concreto de este periodo fue la segmentación de la fuerza laboral y la creación de un mercado de trabajo dual. Para poder aprovechar plenamente el avance en el control de la producción que brindaba el Acuerdo, las corporaciones expandieron su aparato administrativo y de supervisión. Surgen sofisticados sistemas de control de la producción con el objeto de inducir al trabaja-

7 Bruce Steinberg et al. (comps.), U.S. Capitalism in Crisis, New York, URPE, 1978, p. 286.

${ }^{8}$ Richard Lester, As Unions Mature, Princeton, Princeton University Press, 1958, ค. 102.

9 Samuel Bowles, David Gordon y Thomas Weisskopf, Beyond the Wasteland, New York, Anchor Press, 1984, p. 73.

10 Bureau of Labor Statistics (citado en Green op. cit., p. 211 ): Nótese que el Buró del Censo de los Estados Unidos considera que una familia de cuatro personas vive en la pobreza con ingresos de 11203 dólares anuales.

11 Para todo este periodo véase el interesante análisis de Mike Davis, Prisoners of the American Dream, London, Verso Books, 1986, p. 121-124. 
dor a realizar mayores esfuerzos sin tener que utilizar la amenaza del desempleo. ${ }^{12}$ De ahí que la proporción entre trabajadores no productivos y productivos en la industria aumentó de $19.5 \%$ en 1947 a $40.6 \%$ en 1975 . $^{3}$ Además de un mayor número de supervisores, ingenieros, técnicos y expertos en personal, se necesitaron grandes cantidades de empleados administrativos; por tal razón este rubro constituyó la rama de empleo que más aumentó entre 1950 y 1975. Sólo el número de estenógrafos y tipistas en la fuerza laboral aumentó de 1.6 millones a 3.9. Al mismo tiempo, al ser parte de la organización del nuevo proceso productivo, estos trabajadores estaban sujetos a los mismos criterios "científicos" que los obreros.

La mayoría de los empleados administrativos provienen de lo que los economistas llaman el mercado de trabajo secundario o subordinado. Los trabajadores que venden su fuerza de trabajo en este mercado son principalmente mujeres y hombres de las minorías; tienen por lo general menos calificación y nivel educativo que los del mercado laboral primario, en el que predominan hombres blancos. Así, la fuerza laboral del mercado subordinado rara vez está organizada, mientras que la del primario sí lo está. Esta segmentación no es nueva, existe desde los comienzos de la década de 1920 y se centra, principalmente, en la calificación del trabajador. ${ }^{14}$ Si bien esta característica se ha mantenido, dividiendo al trabajador textil del automotriz - gracias a la diferencia en calificación-, a partir de mediados del siglo $\mathrm{XX}$ se ha modificado en forma importante. El mercado laboral subordinado está ahora dominado por trabajadores de servicios cuya mano de obra es principalmente femenina y de bajos ingresos. Así, entre 1950 y 1970 los trabajadores de servicios aumentaron de 15.8 millones a 27.7 , mientras que los obreros industriales aumentaron durante el mismo periodo de 22.8 a 26.6 millo nes. ${ }^{15}$

En este sentido, aunque la mujer constituye el grupo laboral más grande en el mercado de trabajo subordinado, esto también se ve modificado verticalmente por el aumento de negros y extranje. ros. En el caso de los negros la modificación tiene que ver con el éxodo masivo que ocurre desde el sur rural hacia las zonas urbanas $e$ industriales del norte durante la década de 1940. La población negra en el norte y el oeste de Estados Unidos aumentó en $6.5 \mathrm{mi}$ llones entre 1950 y 1966 , es decir $98 \%$ del crecimiento en las zonas urbanas. Por otro lado, la liberalización de las leyes de inmigración, junto con la necesidad de mano de obra barata tanto en el agribusiness del sudoeste como en los talleres manufactureros, incorporó millones de nuevos trabajadores extranjeros al mercado subordinado. La cantidad de latinoamericanos, asiáticos y europeos en Estados Unidos se duplicó entre 1965 y 1970 ; todos ellos son sujetos de una gran explotación, tanto por desconocimiento del medio como por la falta de respaldo socioeconómico que sufre todo inmigrante, y en muchos casos por una situación migratoria ilegal. ${ }^{16}$

12 Bowles, Gordon y Weisskopf, op. cit., p. 74.

13 Green, op. cit., p. 225.

I4 Para una interesante periodización del desarrollo de la clase obrera norteamericana, véase Gordon, Edwards y Reich, op. cit.

${ }_{15}$ Green, op. cit., p. 227.

${ }_{16}$ Green, op. cit., p. 228. 
Esta incorporación masiva de nuevas razas y etnias al mercado laboral agudiza la situación de mercado de trabajo dual para los mismos. La segregación permea al sistema educativo, al aparato político, a las zonas de vivienda y por supuesto al mercado de trabajo. Así no sólo son los niveles salariales más bajos para este sector laboral subordinado, sino que el nivel de subempleo y desempleo es el doble que el del promedio nacional; las mujeres resultan más afectadas que los hombres en el mercado subordinado. Esta es la razón de que el ingreso promedio de una familia negra en 1969 fuera el $61 \%$ del de una familia blanca. ${ }^{17}$

A pesar de que el Acuerdo benefició a algunos trabajadores, principalmente a aquellos que estaban organizados, excluyó por completo a otros. De esta manera la situación se encontraba descansando sobre un segmento de la fuerza laboral, puesto que los no organizados, las mujeres y las minorías no participaban de sus beneficios; también descansaba sobre el crecimiento económico ininterrumpido del sistema; sin embargo, sembró la semilla de su propia inestabilidad, puesto que eliminó la tradicional amenaza del desempleo como palanca en contra del trabajador organizado.

La baja en el ciclo económico que marca las dos primeras fases de la crisis, 1966-1973 y 1976-1979, erosiona el sistema de posguerra. Así, hacia fines de la década de 1960 la cantidad de huelgas salvajes aumentó ocho veces en relación con el periodo anterior y el número de tendencias democráticas disidentes de las direcciones gremiales gozó de un auge que en varios casos tuvo éxito al desplazar a los dirigentes de la década de 1950. Tanto en el gremio metalúrgico, en el cual A.W. Abel desplazó a Larry MacDonald como presidente, como en las bases del gremio minero se promovía la agitación en contra del sindicalismo antidemocrático y a favor de mejores condiciones de trabajo. En 1969 una huelga organizada desde la base gremial movilizó a 45000 mineros del carbón en Ohio, Pennsylvania y West Virginia. En 1975, 62000 mineros pararon como protesta en contra de violaciones al convenio. La productividad por día trabajado declinó precipitadamente entre 1969 y 1977.

II. Las condiciones internacionales, la guerra de Vietnam y la competencia por parte de los países capitalistas reconstruidos en la posguerra, junto con la reducción geográfica de mercados generada por las distintas revoluciones socialistas y nacionalistas, significó que la participación de Estados Unidos en el producto mundial bruto pasó de $50 \%$ a principios de la década de 1950 a $30 \%$ hacia 1973 y a $25 \%$ hacia 1980 . Más aún, a partir de 1964 la tasa de ganancia de las corporaciones norteamericanas tiende a decrecer constantemente. 18

Desde finales de los sesenta empezó a tomar forma el conflicto entre trabajo y capital respecto a la productividad. Los empresarios estimaban entonces que la demanda de trabajo continuaba siendo alta y los sindicatos seguian exigiendo incrementos salariales que

17 Nótese que odho años más tarde la brecha se habia ampliado. La familia negra tenia un ingreso promedio que correspondía a $57 \%$ del de una familia blanca. Véase Green, op. cit., p. 236.

1s Véase Gérard Duménil, Mark Glick y José Rangel, "The Tendency of the Rate of Profit to Fall in the United States", Contemporary Marxism, No. 9, Fall 1984. 
permitieran a sus miembros mantener su poder adquisitivo frente a la inflación, mientras que las ganancias de las corporaciones empezaban a declinar. Estas podían haber sido sostenidas mediante una transferencia de los costos laborales a los precios, pero la creciente competencia internacional (especialmente de la industria automotriz y del acero) hacía de éste un método casi impracticable. También se podría haber recurrido a una mayor automatización de los procesos productivos, pero la introducción de una nueva tecnología resultaba demasiado costosa para la época. La única solución, entonces, fue recurrir a un aumento de la tasa de explotación de los trabajadores mediante una reorganización del trabajo y una aceleración del ritmo de producción. ${ }^{19}$

La reacción de los trabajadores, a fines de la década de 1960 y a principios de la de 1970 , se dio de manera espontánea; se expresó como rebeldía individual por medio del sabotaje, ausentismo, limitación de resultados y otras formas de resistencia. En síntesis, a principios de la década de 1970, quedaba claro para las corporaciones que se requerían soluciones de fondo y no una mera reorganización del trabajo.

A partir de mediados de la década de 1970, la solución que se plantea para resolver este problema es la de "modernizar" la economía norteamericana para responder con más eficiencia a la competencia internacional, tanto en bienes industriales tradicionales como en productos de alta tecnología. Esta modernización implica la eliminación de fuentes de trabajo en las ramas industriales más viejas. De ahí la puesta en marcha de una revolución científico-técnica cuyo efecto ha sido elevar la productividad, eliminar al mismo tiempo a camadas enteras de obreros especializados y reducir el costo de la mano de obra.

De esta manera nos encontramos con viejas corporaciones basadas en industrias tradicionales que reestructuran sus operaciones y desmantelan las anteriores. En febrero de 1986 la corporación Singer Sewing Machine abandonó la producción de máquinas de coser y anunció que desmantelaría sus plantas, para dedicarse de lleno a la industria aeroespacial. Algo similar ocurrió en el caso de General Motors, que en julio de 1985 absorbió a la Electronic Data Systems. Su objetivo era adquirir y reforzar sus intereses en la alta tecnología para poder aprovechar más las posibilidades que el desarrollo del complejo militar-industrial abría gracias a proyectos tales como la "Iniciativa de Defensa Estratégica de la Administración Reagan". ${ }^{20}$ Lo mismo se puede decir de la fusión de las corporaciones General Electric y RCA, cuyo resultado fue la mayor tecnificación de sus procesos productivos, la reubicación de varias de sus plantas en el exterior y la reducción de su fuerza laboral en 39000 trabajadores. ${ }^{21}$ Y la Caterpillar Tractor Company, que anunció en diciembre de $1985 \mathrm{su}$ intención de transformar el sistema de línea de producción en otro en el cual el trabajo sería realizado en células fabriles altamente automatizadas, cuya productividad, computarizada y robotizada, se

19 María Isabel Sen, "Evolución reciente del sindicalismo en Estados Unidos", CIDE. Cuadernos Semestrales. Estados Unidos Perspectiva Latinoamericana, México, Instituto de Estudios de Estados Unidos, núm. 11, 1982, p. 127.

20 Marcy, op. cat., p. xi.

21 Barry Bluestone y Bennett Harrison, The Deindustrialization of America, New York, Basic Books, 1982. 
combinaría con la de talleres fuera de la empresa que se especializarían en partes. Como efecto concreto de este proyecto, Caterpillar, que en 1979 redujo su fuerza laboral de 90000 obreros a 53000 , despidió por lo menos 10000 más y mantuvo los niveles de productividad: ${ }^{22}$

Considerada desde el punto de vista de los trabajadores, la revolución científico-tecnológica ha tenido un impacto casi tan profundo como la revolución industrial. Esta fue la conclusión de un estudio realizado por el comité ejecutivo de la AFL-CIO en $1985 .{ }^{23}$ En este sentido, el estudio apuntaba que durante las dos últimas décadas habian ocurrido cambios estructurales que podían tener implicancias históricas para la clase obrera.

Un buen ejemplo de los efectos de esta revolución es la nueva planta Saturno proyectada por General Motors en Tennessee. Con el criterio de que para poder competir con las corporaciones japonesas la mano de obra norteamericana debía abaratarse por lo menos en 2000 dólares anuales por trabajador, se aplicó todo el avance tecnológico para proyectar una planta automotriz robotizada. Los obreros de Saturno recibirán un salario básico que será del $80 \%$ del de otros trabajadores automotrices. Al mismo tiempo la planta funcionará con sólo una categoría de obreros no calificados y de tres a cinco de obreros calificados. En contraste, las fábricas tradicionales tienen hasta 100 categorías distintas. La antigüedad será eliminada y los aumentos salariales estarán en relación directa con el aumento de la productividad por trabajador. Desde el punto de vista sindical, se eliminan el delegado de sección y la comisión interna, que serán reemplazados por un consenso sindicato-patrones ${ }^{24}$ De hecho, al mantener la segmentación entre industrias en cuanto a la calificación, se plantea la homogeneidad en cuanto a los niveles salariales de los trabajadores y en cuanto a las diferencias dentro del lugar de trabajo.

Pero el esfuerzo "modernizador" no abarca sólo la aplicación de tecnología que abarate los costos de mano de obra. También implica el traslado de empresas hacia países como Taiwan o Singapur cuya tasa de explotación es mucho más elevada, o hacia estados del pa ís que se encuentren "libres" de la influencia sindical. Esta situación se refleja en la declaración de 1980 de Martin Gerber, vicepresidente de la UAW: "La verdadera amenaza [para el movimiento obrero] es la movilidad internacional del capital. En los próximos años vamos a tener que cambiar nuestra perspectiva, desde [organizar] por rama de industria hacia [la organización] internacional',25 Así, en los estados del sur norteamericano se generaron 860000 nuevos trabajos industriales entre 1966 y 1976, pero con salarios un $20 \%$ menores que los del norte. Lo mismo se puede notar de las más de 8000 subsidiarias establecidas entre 1945 y 1970 por las corporaciones norteamericanas en países extranjeros.

En el caso de nuevas ramas de la producción, el sindicalismo norteamericano ha sido incapaz de organizar nuevas estructuras y nuevas zonas geográficas. Un ejemplo claro de esto es la industria

22 Marcy, op. cit., p. 22.

23 The Changing Situation of Workers and Their Unions, a report, by the AFLCIO Comittee on the Evolution of Work, February 1985.

${ }^{24}$ Marcy, op. cit. p. 27.

25 Citado en Green, op. cit. p. 247. 
de la informática y los microcircuitos. En 1955 ocho corporaciones escogieron el valle de Santa Clara, al sur de San Francisco, para instalar sus plantas de semiconductores con la intención de escapar de la zona del Gran San Francisco que está fuertemente sindicalizada y como forma de absorber mano de obra barata proveniente de las zonas rurales. Hacia fines de la década de 1970 , lo que ahora se llama el Valle de Silicona había crecido hasta dar cabida a 1500 empresas con más de 200000 obreros no organizados ${ }^{26} \mathrm{Su}$ contrapartida en el noreste se encuentra en Massachusetts, a lo largo de la ruta 128 y de la carretera I-95; tampoco estos obreros están organizados, a pesar de la fuerte concentración de empresas. Así, el desarrollo de esta industria ha sido espectacular, pero no se ha traducido en mejoras salariales para los trabajadores del rubro.

Por último, hay que tomar en cuenta que el crecimiento de una economia especulativa ha facilitado el desarrollo de numerosas tácticas corporativas basadas en el vaciamiento y la quiebra de empresas como forma de obtener ganancias rápidas y muy altas con una baja inversión inicial. En este sentido, la esfera de las finanzas. tiende a convertirse en un subsistema autónomo dentro de la economía con una enorme capacidad de autoexpansión y con consecuencias funestas para las ramas productivas. ${ }^{27}$

III. El resultado de esto ha sido profundo para los trabajadores. Un detallado estudio publicado por el New York Times sobre la afiliación sindical daba una idea del cambio producido. El gremio metalúrgico (United Steel Workers) "tenía 572000 afiliados el pasado 30 de junio, aproximadamente la mitad de los que tenía en la década de 1970. La afiliación al UAw se redujo 35\%, a 974000 miembros. El sindicato tenía más de un millón y medio de afiliados en la década de 1970". El sindicato del caucho (URW) declinó 33\%, a 106000 afiliados. Los mecánicos (IAM), con 520000 miembros, eran $37 \%$ menos que en 1969. En cuanto a los trabajadores del vestido (ILGWU) la reducción fue de $40 \%$ con relación a 1977 , cuando tenía 350000 afiliados. Entre 1969 y 1985 la Unión Internacional de Tipógrafos se redujo en $50 \%$, a 38000 miembros. En cambio, la Unión Internacional de Empleados de Servicio (SEIU) tuvo un crecimiento dramático, pasó de 505000 afiliados en 1977 a 688000 en 1985.28

En este sentido, si consideramos las estadísticas globales, la cantidad de trabajadores organizados declinó $17 \%$ entre 1980 y 1984 , para llegar a $19 \%$ del total de la fuerza laboral. Si bien $35.9 \%$ de los empleados del Estado se encuentra organizado, sólo $15.6 \%$ de los asalariados en empresas privadas lo está. Asimismo, en el sector servicios sólo $10.6 \%$ se encuentra organizado, mientras que en las ramas industriales el porcentaje llega a 26.5 por ciento. ${ }^{29}$

26 La estructura laboral de la zona se encuentra altamente polarizada entre profesionales y obreros. Si bien los ingenieros electrónicos tenían un ingreso de $\mathbf{8 0} 000$ dólares al año en $1984,75 \%$ de la fuerza laboral compuesta por mujeres y minorías tenía un salario anual que oscilaba entre 6968 y 18304 dólares. San José Mercury News, November 5, 1984, citado en Davis, op. cit. p. 130.

27 Véase "The Casino Society", Business Week, September 16, 1985, y "The Financial Explosion". Monthly Review, Vol. 37, No. 7, December, 1985.

28 The New York Times, October 5, 1985.

${ }^{29}$ Davis, $o p$. cit., p. 147. Nótese que la tendencia decreciente ha continuado en los últimos cuatro años, por lo que se calcula que la proporción de la fuerza de trabajo sindicalizada en los Estados Unidos se acerca a 16 por ciento. 
La base material de este fenómeno es el salto en productividad que ha significado la revolución científico-técnica. En 1977, los 400000 obreros de las principales empresas metalúrgicas producían dos veces más que los 600000 que trabajaban en ellas en 1947. Dos trabajadores que utilicen maquinaria automatizada pueden producir mil radios diarios y reemplazar a 200 obreros. Un obrero en una planta Ford opera una máquina que realiza 500 operaciones antes desarrolladas por 35 a 70 obreros. ${ }^{30}$

El cierre de fábricas, o su traslado a latitudes menos inhóspitas para los patrones, adquirió características de catástrofe entre 1977 y 1982. En este periodo se han perdido más de cuatro millones de trabajos industriales. ${ }^{31}$ Trece millones de trabajadores han sido desplazados por cierres de plantas. De aquellos que pudieron encontrar trabajo una vez despedidos, $60 \%$ gana menos de 7000 dólares anuales. ${ }^{32}$ Un trabajador metalúrgico desempleado, que ganaba 13.50 dólares por hora, recibe 7.50 por hora en un empleo en la industria electrónica. E1 $90 \%$ de los nuevos trabajos está en el sector servicios con muy bajas escalas salariales. De hecho, este sector se ha tornado cada vez más de trabajo intensivo; por ejemplo, un restaurante MacDonald's emplea unos 60 trabajadores. ${ }^{33}$ Uno de cada cinco obreros empleados en industrias relacionadas con el presupuesto militar se verán desempleados en los próximos cinco años. Empresas tales como General Electric han despedido entre 1981 y 1985 cerca de 100000 obreros. $^{34}$

El problema de los cierres no sólo tiene implicaciones para los trabajadores desempleados sino para comunidades enteras. Cuando cerró la fábrica Ford de Mahwah, Nueva Jersey, en 1980, no sólo afectó a 5000 trabajadores, sino también a numerosos comercios, fábricas de autopartes y miles de familias. Lo mismo se puede decir de toda la zona del oeste de Massachusetts, cuyo desarrollo industrial fue importantísimo entre 1830 y 1960 y que hoy en día está en franca decadencia debido al traslado de distintas empresas al sur del país.

Esto se combina también con nuevas tácticas aplicadas en la ofensiva antisindical de los patrones. El lock-out y los trabajadores por agencia han servido para reducir aún más los niveles salariales del obrero. Dijo Ernie Roustelle, representante internacional del sindicato químico (Oil, Chemical and Atomic Workers): "[Los patrones están] amenazando a la gente con que pueden dejarlos fuera del lugar de trabajo y reemplazarlos temporariamente con trabajadores por agencia durante los próximos diez años"' ${ }^{35}$

Comenzando con las numerosas concesiones salariales y de beneficios que hizo la UAW a Chrysler entre 1979 y 1981 , las corporaciones forzaron un retroceso en las conquistas sindicales norteamerica-

${ }^{30}$ Esta situación no es totalmente nueva. En 1960 el gremio portuario firmó un acuerdo de mecanización y modernización que duplicó la productividad, redujo los costos de mano de obra un $30 \%$, redujo la fuerza de trabajo un $50 \%$ y aumentó la tasa de accidentes laborales. Véase Green, op. cit., p. 213.

${ }^{31}$ Steinberg, Fortune, November 28, 1983, citando a Candee Harris, una economista de la Brookings Institution.

32 Joint Economic Committee of Congress Report, December 1986.

33 Steinberg, op. cit.

34 U.S. Bureau of Labor Statistics.

${ }^{35}$ In These Times, January 21-27, 1987. 
nas. Durante la primera mitad de 1982 , casi $60 \%$ de los sindicatos aceptó congelamientos o reducciones salariales, bajo amenaza de cierres de plantas y traslados. La compañía de transporte de pasajeros Greyhound forzó a una huelga de siete semanas en 1983 hasta imponer una reducción salarial de $15 \%$. Aerolíneas y frigoríficos hicieron lo mismo. Estos últimos lograron imponer reducciones salariales de 40 a 60 por ciento ${ }^{36}$

El efecto social de esta situación es una fuente de preocupación para medios oficiales y voceros empresariales. Definiendo a la clase media casi exclusivamente por su ingreso, distintos estudios apuntan hacia la pauperización y la reducción numérica de este sector. La Reserva Federal de Boston hizo notar en un estudio realizado en 1986 que la clase media (20 000 a 50000 dólares anuales) se había reducido en $5.1 \%$ entre 1973 y 1984 , mientras que la clase baja (19 999 dólares o menos) había aumentado en $36.4 \%$ de la población y la rica (más de 50000 dólares anuales) creció $0.8 \%{ }^{37}$ Lo mismo fue apuntado por la revista Fortune; de acuerdo con esta fuente la polarización de ingresos se ha agudizado mucho en los últimos veinte años. El 20\% más rico de las familias norteamericanas tiene ingresos promedio nueve veces mayor que el $20 \%$ menos pudiente; a diferencia de hace una década cuando la brecha era de siete veces. La preocupación de Fortune se relaciona directamente con el futuro del mercado interno y las restricciones en la capacidad adquisitiva del consumidor norteamericano. ${ }^{38}$ De hecho, según el Buró de Censos de Estados Unidos, en 1983 la cantidad de familias por debajo del nivel de "pobreza" era $14 \%$ del total e iba en aumento. ${ }^{39}$ Es claro que esta situación afecta en forma desigual a los distintos grupos que conforman a la población de los Estados Unidos. Si bien sólo el $11.5 \%$ de los blancos está por debajo del límite de pobreza, entre los latinos esto sube a $28.4 \%$ y entre los negros a $33.8 \% .^{40}$ En 1973 los 12.4 millones de familias más pobres de los Estados Unidos promediaban un ingreso anual total de 9639 dólares mientras que en 1985 su ingreso era sólo de 6529 dólares. ${ }^{41}$

Esta situación no afecta solamente al movimiento obrero, también ha golpeado duramente a los granjeros norteamericanos hasta el punto de casi hacerlos desaparecer como clase. La revolución científico-técnica ha alcanzado a las grandes corporaciones agropecuarias, tales como Ralston Purina y Del Monte. Las granjas medianas están desapareciendo, pues sus tierras son adquiridas por operadores más eficientes ${ }^{42}$ De hecho, el Buró del Censo informó que 399000 familias abandonaron el campo en 1985, reduciendo el total de la población rural a $2.2 \%$ del total ${ }^{43}$ Del millón de granjas que todavía existen, sólo 50000 concentran $75 \%$ de la producción,

36 Davis, op. cit., p. 141.

${ }^{37}$ Kathrine L. Bradbury, "The Shrinking Middle Class", New England Economic Review, September-October, 1986. (A Federal Reserve Bank of Boston Study.)

38 Steinberg, op. cit., p. 77.

39 U.S. Bureau of the Census, Current Population Reports, Series P-60, No. 149.

40 Bureau of Labor Statistics.

41 The New York Times, March 22, 1987. Nótese que durante este periodo ha habido un serio proceso inflacionario, por lo que el salario real es aún menor.

${ }_{42}$ The Wall Street Journal, December 9, 1984.

43 U.S. Census Bureau Report, January 9, 1986, citado en USA Today, weekend edition, January 10-12, 1986. 
por lo que se calcula que $50 \%$ del total restante desaparecerá durante la próxima década ${ }^{4}$

Esta situación entronca directamente con la recomposicion de la clase obrera norteamericana. Desde principios de la década de 1930 no había en Estados Unidos un flujo tan grande de gente del campo hacia la ciudad. Los trabajadores norteamericanos actuales no sólo son étnicamente diversos, sino que una vez más tienen un componente que proviene de culturas y formas de vida no industriales.

IV. Esta situación está llevando a una crisis de las pautas culturales y a legitimar el sistema entre los trabajadores. Tal situación ya se notaba a principios de la década de 1970, como lo demuestra Studs Terkel en su excelente obra Working. Entre otros muchos, Terkel entrevistó a un obrero metalúrgico llamado Mike Lefebvre que le explicó los cambios en el mundo del trabajador. Dijo Lefebvre que él estaba dispuesto a trabajar duro para pagar sus deudas y mandar a los hijos a la universidad, pero que le molestaba la falta de autonomía y dignidad en el trabajo. Y recordó una pelea que tuvo con su nuevo supervisor en la que le gritó: "Vine a trabajar no a andar de rodillas"; habiendo perdido su lucha con el supervisor estaba desesperanzado. “¿A quién le vas a pegar?”, le preguntó a Terkel. "No puedes pegarle a General Motors, no puedes pegarle a nadie en Washington, no puedes pegarle al sistema." 45

Esta idea se basa en que la clase dominante de Estados Unidos ha logrado imponer sus intereses como los intereses universales. A diferencia del siglo XIX y primeras décadas del siglo $\mathrm{XX}$, a partir de 1950 ser anticapitalista se percibe como ser antinorteamericano. En ese sentido el mismo concepto de "clase" ha desaparecido del lenguaje cotidiano y de los medios de comunicación. Los trabajadores son definidos como individuos en términos biológicos (negros, blancos, mujeres, hombres, ancianos, etc.) y en términos de consumo (ricos, medios y pobres). Es así como los obreros automotrices de la planta cerrada por Ford en Mahwah, Nueva Jersey, manifestaban sentimientos de impotencia y culpa ante el problema de quedarse desempleados después de años de estabilidad laboral. ${ }^{46}$

A fines de la década de 1960 se da respuesta a la alienación que genera el sistema de posguerra; lo que sucede entonces es una fuga de los trabajadores organizados hacia los barrios suburbanos. Parece ser que al considerar el trabajo industrial como una "condena de por vida" se reemplazaron las expectativas de movilidad social por las de movilidad residencial; sin embargo, este cambio no trajo consigo la adopción de los valores de los sectores medios. Green apunta que en vez de integrarse a la comunidad suburbana clasemediera, los obreros suburbanos reproducen una cultura obrera pero con un grado mayor de tensión ya que han abandonado las redes de apoyo desarrolladas durante generaciones en los barrios obreros urbanos. ${ }^{47}$

14 Congressional Office of Technology Assessment Report, citado en Workers World, September 25, 1986.

${ }_{45}$ Studs Terkel, Working, New York, Vintage, 1972.

${ }^{46}$ Acerca de este tema véase Vicente Navarro, "The Road Ahead", Monthly Review, Vol. 37, No. 3, July-August. 1985. En cuanto a Ford en Mahwah, véase la entrevista con el obrero Carl Glenn. Workers World Supplement, May 1, 1986.

47 Gren, op. cit., p. 217, cita los estudios de Herbert Gans (The Levittowners, 1967) y Bennett Berger (Working Class Suburb, 1960), como las bases de sus conclusiones más actuales. 
Para principios de la década de 1970 era otra la generación que entraba a las plantas. Con un mayor nivel de educación, más jóvenes y, en algunos casos, imbuidos del radicalismo de los sesenta, y marcados a fuego por la experiencia de Vietnam, estos trabajadores no contaban en general con una tradición de lealtad hacia los sindicatos y no se disciplinaban tan fácilmente por miedo a la pobreza o la inseguridad; sus valores y expectativas iban más allá de los beneficios materiales que se obtuvieran en la negociación colectiva. En el fondo eran producto de la profunda crisis que marcó a la sociedad norteamericana en ese entonces, y por lo tanto se tornaron en críticos del sistema.

La misma ofensiva de los patrones, junto con la falta de salidas individuales, ha llevado a un resurgimiento del radicalismo decimonónico. Esta concepción divide la sociedad entre productores y capitalistas, definiendo a los productores como todos aquellos que trabajan con las manos o prestan servicios necesarios a la producción. El tener una definición tan amplia de "productor" permite plantear el conflicto social con más amplitud, ligando a obreros, empleados, granjeros y pequeños comerciantes de la comunidad en contra de los "parásitos financieros, banqueros, profesionales" ${ }^{48} \mathrm{De}$ esta manera se centra el problema una vez más sobre el control de la producción e inclusive se llega a cuestionar la propiedad privada y su función social. El nuevo consenso lo sintetizaron miembros de la UAW, Local 22 en Detroit, amenazados por el cierre de una planta de Cadillac-General Motors; declararon: "ha hecho demasiado dinero con nosotros como para cerrar esta planta" ${ }^{49}$ Lo mismo opinaron obreros de General Foods en Chicago: "No sólo sufrimos los obreros, sino toda la comunidad, ya que muchos pequeñós comerciantes dependen de nosotros. Si no hacemos algo pronto, toda la zona oeste de Chicago va a parecer una ciudad fantasma." 50

De ahí que en varios casos se note que la lucha contra el cierre de las fuentes de trabajo se da no sólo en los sindicatos sino en la comunidad. Asi, ante el peligro de cierre o traslado de distintas plantas fabriles en el noreste, los trabajadores apoyados por la comunidad decidieron asumir el control y mantenerlas en funcionamiento ${ }^{51}$

Asimismo, esta situación se ha traducido en una crisis en cuanto al movimiento obrero organizado. Ya se señaló que la cantidad de huelgas "salvajes", organizadas desde la base venía creciendo lentamente desde principios de la década de 1970. El momento de cambio parece haber sido la huelga de los mineros del carbón en 1977 y 1978. Este conflicto abarcó toda la industria y duró más de 100 días, y estuvo organizado por tendencias democráticas en el punto de

48 Para un buen desarrollo de este concepto a fïnes del siglo XIX, veáse León Fink, Workingmen's Democracy, Chicago University of lllinois Press, 1983. Nótese que el socialismo "debsiano" tenía una base similar, y que el Partido Comunista en su época de auge, durante la década de 1930, planteaba algo similar bajo la consigna: "El comunismo es el americanismo del siglo XX".

49 Véase las declaraciones en People's Daily World, November 13, 1986.

50 Véase Workers World Special Supplement, May 1, 1986.

51 Dos buenos ejemplos de esto son los casos de Campbell Works, en Youngstown, Ohio, y la Heat Transfer Division de American Standard, en Buffalo, Nueva York. En ambos casos la comunidad votó por la adquisición de la fábrica en cuestión y por ponerlas en funcionamiento bajo la dirección del sindicato respectivo. Véase Green, op. cit. p. 246. 
producción. Asimismo, los mineros contaron con el apoyo de sus comunidades que se rehusaron a integrar los batallones de la Guardia Nacional enviados a reprimir el conflicto, y también con el de los granjeros del medio oeste que enviaron caravanas de coches cargados con alimentos. Por otro lado, las direcciones sindicales a nivel nacional no se movilizaron en apoyo al conflicto, a diferencia de secciones individuales, particularmente automotrices y metalúrgicos, que sí lo hicieron. El conflicto logró un importante triunfo a pesar de la violencia ejercida por los patrones y el Estado nacional, y a pesar de la falta de apoyo del sindicato minero. Su impacto se debió no sólo al éxito logrado, sino a que fue llevado a cabo nacionalmente desde la base y en contra de la estructura sindical. En la práctica ejemplificó el nuevo radicalismo. Dijo Hubert Steele del Distrito 28 de la United Mine Workers (UMW) en Castlewood, Virginia: "[El presidente de la UMW Arnold] Miller está trabajando para la BCOA [patrones], y el presidente de los Estados Unidos y el gobierno también".52

La situación se agudiza al asumir el poder en enero de 1981 la nueva administración Reagan, que casi inmediatamente desata una profunda ofensiva contra el movimiento obrero. Los subsidios escolares, el seguro de desempleo, el seguro social, los préstamos a minorías, los servicios sociales y los seguros médicos fueron reducidos o eliminados. Conquistas obreras tales como OSHA (la administración de salud y seguridad ocupacional) y los programas de trabajo para jóvenes fueron suprimidos. Se eliminaron las restricciones sobre el trabajo infantil y doméstico. Se redujeron los recursos del National Labor Relations Board (NLRB) en un momento en que el número de conflictos que debían resolverse pasó de los $30000 .{ }^{53} \mathrm{La}$ imagen de los dirigentes del sindicato de controladores del aire (PATCO) cuando eran llevados a la cárcel en cadenas mientras el gobierno despedía a 12000 trabajadores debido al conflicto desarrollado en 1981, y la represión desatada contra los ferroviarios en huelga en 1982, hizo una fuerte impresión en el ambiente gremial.

A pesar de las expectativas de los analistas, el cambio en la percepción del trabajador fue suficiente para desatar una serie de movilizaciones como no se habían visto desde la década de 1930. El 3 de ma yo de 1981 más de 100000 personas marcharon en las calles de Washington con la consigna: "Dinero para los niños de Atlanta, no para la Junta de El Salvador." La importancia de tal acto fue que aglutinó por primera vez a los tradicionales sectores estudiantiles, pacifistas e izquierdistas como una multiplicidad de comités de barrios, sindicatos de base y tendencias obreras democráticas.

Pero donde se hizo más evidente el cambio fue en la movilización del 19 de septiembre de 1981, conocida como el "Día de Solidaridad", organizada por la AFL-CIO para oponerse a la política antiobrera de Reagan. Nadie esperaba una gran movilización, sin embargo unos 600000 trabajadores se desplazaron ese día a

52 Guardian, New York, March 27, 1978.

53 Nótese que en 1957 la cantidad de casos que manejó el NLRB (Departamento Nacional de Relaciones Laborales) fue 922 . El $90 \%$ de los nuevos casos tenían que ver con violaciones a las leyes laborales debido a despidos por actividad sindical, casi siempre por intentos de organizar sindicatos. Véase Paul Weiler, "Promises to Keep: Securing Workers' Rights to Self-Organization Under the NLRB", Harvard Law Review, Vol. 96, No. 8, June 1983. 
Washington en lo que fue la movilización obrera más grande de la historia norteamericana. Miles de trabajadores llegaron de todas partes del país viajando en autobús, coche o tren para no quebrar la huelga de PATCO. Estuvieron representados todos los gremios, incluyendo a los disidentes de la AFL-CIO y a las tendencias de izquierda. Las blandas consignas provistas por los organizadores fueron reemplazadas por otras escritas a mano: "Ronald Reagan no vale nada, que lo manden de vuelta a Hollywood", "Ronnie, jode a Nancy, no a nosotros". Asimismo, no permitieron que hablara ningún político; Pete Seeger, un conocido folklorista ligado al partido comunista, fue largamente vitoreado. ${ }^{54}$

Estos datos apuntan hacia cambios en la manera en que el trabajador percibe su relación con el Estado, los patrones, la dirigencia sindical y, en última instancia, el sistema. ${ }^{55}$ Sin embargo, las décadas del Acuerdo de posguerra y el énfasis sindical, cuando las conquistas se obtienen por la vía de la negociación y del lobby (grupo de presión) político, hacen que cuando las corporaciones rompen esa convivencia los trabajadores no están preparados, ni tienen en su acervo de experiencia gremial las condiciones necesarias para llevar adelante sus reivindicaciones en medio de una agudización de la lucha de clases.

Tal estado de cosas se ve con claridad si consideramos la situación del sindicato metalúrgico (USW) entre 1982 y 1983. En ese momento los patrones, basados en el decaimiento del mercado y una capacidad ociosa del $66 \%$, le plantearon al sindicato la necesidad de hacer concesiones salariales que mejoraran la liquidez de las empresas; en apariencia esto facilitaría la modernización de la industria y aseguraría las fuentes de trabajo. La USW, dirigida por Lloyd McBride, ya había decidido aceptar la propuesta, a pesar de que las concesiones dadas en 1981 a la U.S. Steel, la principal corporación de la industria, no dieron como resultado la modernización sino la compra, en febrero de 1982, de Marathon Oil por la empresa. ${ }^{56} \mathrm{La}$ realidad era que la situación financiera de las empresas no era buena, si bien estaban lejos de la bancarrota, y que a fines de 1982, 125000 metalúrgicos, $42 \%$ del total, habían perdido su trabajo.

Reunidos en Pittsburgh, los presidentes de las diferentes secciones de la usw fueron presentados por McBride con el resultado de sus negociaciones. El nuevo convenio significaba que cada trabajador metalúrgico empleado por tiempo completo perdería 5282.32 dólares anuales. Puesto que el nuevo contrato duraría 44 meses, esto implicaba una transferencia de ingresos de los trabajadores a los patrones de casi cinco mil millones de dólares. Además, se incluía una lista de 75 secciones que quedarían fuera del convenio y que deberían negociar por separado con las empresas, ${ }^{57}$ de 372 secciones, 141 votaron a favor y 231 en contra, incluyendo a los 75 excluidos y

54 Véase Pablo A. Pozzi, "El movimiento de masas norteamericano", Le Monde Diplomatique en español, 20 de noviembre de 1982.

${ }^{55}$ Como plantea David Montgomery en sus estudios sobre el control obrero de la producción, éste encierra elementos socialistas cuestionadores del sistema, si bien no se traducen en una acción política concreta.

56 Jack Metzgar, "Would Wage Concessions Help the Steel Industry?", Labor Research Review, Winter 1983.

57 Jack Metzgar, "The Humbling of the Steelworkers", Socialist Review, Vol. 14, No. 3-4, May-August, 1984. 
a unos 70 "disidentes" de la tendencia democrática de la USW.

A partir de ese momento se desató una fuerte campaña de las empresas y los medios de comunicación en contra de los trabajadores metalúrgicos. La USW se rehusaba a encabezar un plan de lucha. Sin embargo, la base sindical demandaba un programa que rechazara las concesiones, aunque implicara "suicidarse". Hacia marzo de 1983 los cuadros medios de la USW, sintiéndose desorientados e incapaces de desarrollar una salida constructiva a la situación, terminaron aceptando un contrato similar al anteriormente rechazado, pero cuyos recortes salariales eran menores. Si bien el gremio había sido derrotado, y con él los obreros industriales norteamericanos -puesto que el contrato metalúrgico es la vara con la que se miden los demás-, la situación en cuanto a la base sindical había cambiado. A fines de 1983 la lucha por un gremio democrático y combativo ganó la calle con una ferocidad no vista en décadas. En la zona de Pittsburgh la tendencia democrática del sindicato organizó una coalición comunal que propuso la creación de un organismo municipal que asumiera el control y modernizara las fábricas metalúrgicas del valle de Monongahela. ${ }^{58}$ Mientras tanto en Baltimore y otras ciudades se han desarrollado iniciativas organizando a obreros y desempleados en planes municipales de lucha.

V. Es evidente que el principal resultado que se puede medir de la recomposición de la clase obrera se da en el plano político. Considerando el alto grado de abstencionismo en las últimas elecciones presidenciales (por encima del $46 \%$ ) veremos que Reagan resultó electo sólo por el $26.7 \%$ de los votantes en 1980 y por el $29.8 \%$ en 1984. Cincuenta millones de norteamericanos en edad de votar no se molestaron en empadronarse en 1984, y de los que sí lo hicieron, 35 millones no asistieron a las urnas. De estos 85 millones de personas, el $46 \%$ se consideran independientes, el $80 \%$ son blancos, el $83 \%$ tienen educación secundaria o menos, el $72 \%$ tienen entre 18 y 44 años de edad. En cambio, votaron el $77 \%$ de los profesionales, pero sólo el $44 \%$ de los obreros industriales. De hecho, si los obreros, los negros, los de origen hispano y los desempleados hubieran votado en 1984 en un mismo porcentaje que los profesionales con ingresos de más de 25000 dólares anuales, y se hubiera mantenido la distribución socioétnica del voto, entonces el candidato demócrata, Walter Mondale, habría triunfado arrolladoramente. ${ }^{59}$

La clave del problema la da una encuesta realizada en 1980 . Entre 60 y $70 \%$ de los norteamericanos indicó que no percibía mucha diferencia entre el Partido Republicano y el Demócrata; 60 40\% de los norteamericanos se autodefine como "independiente", 37\% como demócrata y $24 \%$ como republicano, lo cual refleja un gran aumento en la cantidad de los que no se consideran de ningún partido. Así, más que realineamiento nos encontramos con que Estados Unidos está sufriendo un desalineamiento político. The New York Times puso en un editorial de 1984: "las diferencias entre ambos partidos son incómodamente estrechas". ${ }^{61}$

58 Labor Research Review, Summer 1983.

59 "Left and the Elections", Guardian, New York, November 21, 1984.

60 Vicente Navarro, op. cit., p. 43.

61 The New York Times, August 26, 1984. 
Sin embargo, en la campaña electoral de 1988 se nota que la candidatura del reverendo Jesse Jackson ha suscitado la adhesión tanto de la comunidad negra como de los trabajadores y granjeros blancos. Esto es importante puesto que cuatro años antes, en la campaña electoral de 1984, Jackson logró un importante apoyo entre los trabajadores y la comunidad negra, pero no entre los blancos. Considerando su raza y su discurso combativo, que ha sido presentado por los medios de comunicación como "comunista", el peso electoral que ha alcanzado indica que los cambios anteriormente apuntados comienzan a tener efecto en la política. En la campaña de 1988 se encontraban junto a Jackson dirigentes sindicales como William Winpisinger, presidente de la International Association of Machinists (mecánicos) y Ken Blaylock, presidente de la American Federation of Government Employees (empleados del Estado); de hecho, un estado tradicionalmente conservador como Wisconsin, cuya comunidad negra es casi inexistente y cuya fuerza política siempre ha sido definida por la alianza entre trabajadores y granjeros (Farmer-Labor Democratic Party), aceptó con beneplácito su candidatura. La principal razón, según el Christian Science Monitor, es "el cambio en actitudes raciales que ahora permiten que los blancos apoyen a un candidato negro". 62

Es evidente que los cambios registrados en la composición de la clase obrera norteamericana producen cambios en la conciencia. Retomando la cita inicial de Enrico Porente podemos decir que el "tercer renacimiento" está en camino, pero que los obstáculos son muchos. La concentración y movilidad del capital mantiene a los trabajadores a la defensiva; sin embargo, es evidente que la crisis del sistema junto con su incapacidad de preservar la prosperidad de importantes sectores de trabajadores ha generado una crisis de legitimidad y un cambio en los patrones de conducta. Los cambios generados a raiz de la crisis de 1929 dieron como resultado la organización de los sindicatos por rama industrial, la cio; también se produjo un auge de la izquierda en el plano político; y por último, se sintetizaron en las transformaciones del New Deal y de Franklin Delano Roosevelt. Los cambios de la década de 1980 abren nuevas posibilidades. Como dijo el gran folklorista norteamericano Woody Guthrie: "debemos cambiar nuestros anteojos para ver luz donde quieren que veamos oscuridad, para ver esperanza donde quieren que veamos desesperanza, y para ver posibilidades de cambio cuando quieren que quedemos atrapados en las arenas movedizas del pesimismo continuo". 63

Buenos Aires

13 de junio de 1988 